\title{
Influências da educação matemática inclusiva no pacto nacional pela alfabetização na idade certa
}

Influences of mathematics education inclusive national pact literacy at the right age

\author{
Jozeildo Kleberson Barbosa ${ }^{1}$
}

\section{Resumo}

Qual a influência da Educação Matemática Inclusiva na formação continuada oferecida pelo PNAIC? Esperamos contribuir para reflexões sobre o que é considerado um ensino de Matemática inclusivo, o que é uma Alfabetização Matemática Inclusiva dentro do programa e as possíveis implicações na formação de alfabetizadores. Consideramos que essa área de conhecimento do currículo, ainda, contribui de maneira significativa para o fracasso escolar e exclusão. A prática comum para o ensino nas nossas escolas não está a serviço da aprendizagem de todos os alunos, é um processo excludente, onde o "modus operandi" se resume a exposição oral do conteúdo e exercícios de aplicação. Percebemos fortes indicativos da Educação Matemática Inclusiva no material do PNAIC, onde são propostas novas interpretações e alternativas de ação pedagógica com vistas à inclusão de todos os alunos nos processos de ensino e aprendizagem. Percebe-se uma articulação entre a Educação Inclusiva e a Educação Matemática dentro do material de formação do PNAIC, oportunizando a possibilidade de diálogo entre a Educação Matemática Inclusiva e as ações formativas vivenciadas pelos professores, propiciando uma Alfabetização Matemática Inclusiva.

Palavras-chave: Educação matemática. Educação matemática inclusiva. PNAIC. Formação de professores.

\section{Introdução}

Nesse trabalho trazemos um estudo sobre nossas percepções em relação à Educação Matemática Inclusiva na formação continuada oferecida pelo Pacto Nacional de Alfabetização na Idade Certa (PNAIC). Entendemos que atualmente ao abordar temas que envolvem a inclusão de alunos, o foco das atenções não são as dificuldades específicas das crianças, mas como os educadores podem

\footnotetext{
${ }^{1}$ Doutor em Educação: Currículo pela PUC-SP, Pós-doutorando em Educação pela Universidade Presbiteriana Mackenzie, Diretor de escola, E-mail.: ildojz@yahoo.com.
} 
dar respostas a essas necessidades, respeitando a diversidade de cada indivíduo. (FERNANDES; HEALY, 2007)

Para esse momento, nosso objetivo é analisar aspectos relacionados à Educação Matemática Inclusiva no material de formação do curso oferecido pelo PNAIC. Desde já destacamos que consideramos a prática inclusiva como uma necessidade para a Educação Especial, como também para a Educação do Campo, Educação Indígena, Quilombola e Educação para as relações ÉtnicoRaciais. Como procedimento metodológico realizamos uma pesquisa documental no material de formação e em estudos sobre a Educação Matemática Inclusiva.

Esperamos contribuir para reflexões sobre o que é considerado um ensino inclusivo de Matemática, o que é uma Alfabetização Matemática Inclusiva dentro do PNAIC e quais as possíveis implicações na formação de alfabetizadores para uma prática de ensino de Matemática que combata a exclusão educacional.

\section{PNAIC: uma proposta de Educação Inclusiva?}

O PNAIC foi instituído pela Portaria no 867/2012 (BRASIL, 2012b). No início o governo federal buscou fortalecer o sentido de "pacto" para designar o programa, mas há a consolidação do termo PNAIC para referenciá-lo. Sua proposta é a alfabetização dos alunos até os oito anos, idade considerada adequada para a consolidação desse processo.

O programa prevê a articulação do Estado em seus três níveis (federal, estadual e municipal) para as ações previstas. Por meio de parceria com as Instituições de Ensino Superior (IES), em sua maioria universidades públicas, o PNAIC elaborou o material utilizado no curso de formação e realizou a capacitação dos alfabetizadores. O curso oferecido aconteceu durante 2013 (língua materna), 2014 (Matemática), 2015 (interdisciplinaridade) e 2016 (avaliações externas). O material utilizado, mesmo possuindo uma temática como foco, buscava contemplar várias situações encontradas nas classes de 
alfabetização, tais como: organização do trabalho pedagógico, currículo, avaliação, processo inclusivo, etc.

Já em seu discurso institucional, observamos o caráter inclusivo do PNAIC ao definir na Portaria 867/2012, em seu artigo 5ำ no primeiro inciso:

Art. 5 As ações do Pacto tem por objetivos: I - garantir que todos os estudantes dos sistemas públicos de ensino estejam alfabetizados, em Língua Portuguesa e em Matemática, até o final do $3^{\circ}$ ano do ensino fundamental; [...] (BRASIL, 2012b, s/n) (grifo nosso).

Ao colocar que "todos" os alunos estejam alfabetizados até o $3^{\circ}$ ano do ensino fundamental percebemos a afirmação como um fator de inclusão, pois atualmente as classes regulares vêm recebendo cada vez mais alunos, entre esses, crianças antes somente atendidas nas escolas de Educação Especial.

Entre os objetivos da formação oferecida, destacamos um, "compreender e desenvolver estratégias de inclusão de crianças com deficiência visual, auditiva, motora e intelectual, bem como crianças com distúrbios de aprendizagem no cotidiano da sala de aula" (BRASIL, 2012a), onde consideramos ser preciso que os professores realizem uma mediação pedagógica inclusiva entre o currículo escolar e as crianças, destacamos a área de Matemática. Em seu discurso, o programa afirma buscar "refletir sobre currículo e ação didática no ciclo de alfabetização, na perspectiva da integração entre componentes curriculares e da inclusão". (BRASIL, 2015a, p.06)

Refletimos que qualquer proposta educativa, na perspectiva que abordamos nesse trabalho, precisa considerar questões como:

A Educação Inclusiva que estamos oferecendo aos nossos alunos com necessidades educacionais especiais está dando a eles as mesmas oportunidades dadas aos alunos que se enquadram nos padrões normais? Estamos certos de que os currículos existentes e aplicados nas escolas atualmente atendem satisfatoriamente aos anseios dos sujeitos da educação a ponto de pretendermos que todos os cumpram? (FERNANDES; HEALY, 2007, p. 61).

A educação proporciona a emancipação social e é um direito necessário e fundamental no combate ao preconceito, à discriminação, à intolerância e à exclusão. Algo que historicamente vem sendo negado aos alunos com 
Necessidades Educacionais Especiais (NEE). A deficiência vem sendo interpretada como uma limitação do sujeito, uma forma de incapacidade, doença, impureza, deformidade, impedindo a plena participação desse sujeito na vida social. (KRANZ, 2015)

Políticas públicas no âmbito educacional têm sido pensadas e implementadas para que a escola se torne inclusiva. Entretanto,

[...] se a escola deve se tornar inclusiva é porque ela não o tem sido, ainda que os preceitos constitucionais nos apontem para uma visão de sociedade justa e igualitária, sem qualquer tipo de discriminação. De fato, desde que foi inventada, a escola não tem considerado as diferenças entre os alunos, organizando-se com base na indiferença a essas diferenças (BRASIL, 2014a, p. 07).

Fernandes e Healy (2007, p. 59) consideram a construção de uma escola aberta e acolhedora das diferenças com um novo paradigma educacional no Brasil. Este "paradigma tem levado a busca de uma necessária transformação da escola e das alternativas pedagógicas com o objetivo de promover uma educação para todos nas escolas regulares". Asseveramos que a inclusão exige mais do que leis. Para as autoras, a inclusão exige uma atenção adequada, o oferecimento de materiais, salas de recursos e equipes especializadas que visitem as escolas eventualmente, são necessários, mas não suficientes. Para as autoras, os problemas que surgem no dia a dia nas aulas transcendem esse âmbito reduzido, atingindo a responsabilidade da equipe docente.

Não bastam, também, os prometidos apoios institucionais, sem a participação efetiva do aluno, e principalmente, sem o professor. Na verdade, nós não encontramos professores que afirmem estarem preparados para receber em classe um aluno com necessidades educacionais especiais. Eles reconhecem que a inclusão é um processo que exige aperfeiçoamento constante, no entanto, declaram que não receberam formação para trabalhar com educandos portadores de necessidades educacionais especiais, seja em sua formação inicial ou continuada. (FERNANDES; HEALY, 2007, p. 73).

Segundo Moreira (2015) embora o termo inclusão seja bastante familiar aos professores, pode ser aplicado a distintos contextos. Para o autor para muitos professores, principalmente os de Matemática, "o sentido etimológico da palavra não pertence à sua sala de aula ou à escola regular, negando a uma quantidade 
significativa da população oportunidades de acesso à Educação, à convivência social, aos serviços, entre outros direitos imprescindíveis para aqueles que vivem em sociedade". (MOREIRA, 2015, p. 512).

Nesse sentido, as considerações desse estudo são significativas, pois estamos analisando um programa de formação continuada que mesmo não tendo a Educação Inclusiva como foco central de suas ações, possui indicações que podem ser significativas para fomentar ações nas classes de alfabetização.

Kranz (2014) defende que quando as diferenças são incluídas no espaço da escola, cabe a essa instituição, e ao sistema ao qual ela está vinculada:

[...] pensar em políticas, projetos, ações e práticas pedagógicas que realmente possam torná-la competente para que essa inclusão não represente apenas a matrícula escolar. Torna-se, assim, necessário que essa escola, que historicamente nunca foi para todos, caminhe no sentido de efetivamente incluir todos os diferentes, garantindo-lhes o acesso, a permanência, a participação e a efetiva aprendizagem e desenvolvimento. (KRANZ, 2014, p. 216).

Para Stainback e Stainback (1996) os educadores comprometidos com a inclusão possuem os seguintes princípios pedagógicos: 1) estão mais interessados naquilo que o aluno deseja aprender do que nos rótulos sobre ele; 2) respeitam o potencial de cada aluno e acreditam na sua capacidade de aprender; 3) acreditam que todos conseguem desenvolver habilidades básicas; 4) buscam informações sobre os recursos necessários para dar maior suporte e mais oportunidades de aprendizagem; 5) utilizam as experiências de vida como fatores motivadores; 6) aprendem com seus alunos e investigam como eles aprendem.

Entendemos que na perspectiva de uma Educação Inclusiva, é importante a promover processos educativos que contemplem as necessidades de todos os alunos, sejam eles estudantes com NEE ou mesmo os considerados "normais" com diferenças socioculturais.

Vygotski (1997, p. 72) indica que o sistema educacional, em relação aos alunos NEE, "deve perder seu caráter especial e assim se converter em uma parte do trabalho educativo geral". Devemos oportunizar para todos, independentemente de sua constituição, um atendimento pedagógico de 
qualidade, pois a "orientação para a eliminação total de tudo o que agrava o defeito constitui a tarefa da escola". Assim, a escola perde sua visão homogeneidade e segregacionismo.

A Política Nacional de Educação Especial na Perspectiva da Educação Inclusiva (BRASIL, 2008, p. 7) é uma ação de referencia para a escola inclusiva e traz como objetivo da inclusão o "acesso, a participação e a aprendizagem dos alunos com deficiência, transtornos globais do desenvolvimento e altas habilidades/superdotação nas escolas regulares".

Para Fernandes e Healy (2010) apesar das leis destinadas a normatizar o processo de inclusão de alunos NEE, muitas pessoas ligadas à Educação afirmam não se sentirem preparadas para enfrentar tal desafio.

Nem sempre nossas concepções encontram respaldo nas práticas cotidianas e nos aspectos institucionais. Na verdade, nota-se que a partir das políticas de inclusão há a necessidade de preparar a comunidade educacional para receber esses alunos. Dentre as muitas incertezas, singularidades e conflitos de valores que ocupam nossas mentes, certamente as questões que se relacionam as nossas ações pedagógicas têm um papel central (FERNANDES; HEALY, 2010, p. 1112-1113).

Kranz (2015, p. 03) considera que a educação se coloca como inclusiva quando se orienta por uma "concepção de diferença pautada em questionamentos acerca de sua produção cultural e social, na sua mutabilidade constante, na sua valorização enquanto produtora de ambientes instigantes, participativos e desafiadores para todos os sujeitos".

Concebemos que as possibilidades de construção ou não de uma escola inclusiva estão diretamente ligadas às concepções que orientam as ações pedagógicas dentro de seus muros. E o que seria uma Educação Matemática Inclusiva? Buscamos orientar essa indagação no próximo tópico.

\section{Educação Matemática Inclusiva no PNAIC}

Antes de adentrarmos nas concepções do PNAIC, julgamos importante destacar que este programa de formação busca que as crianças estejam 
alfabetizadas até $03^{\circ}$ ano do ensino fundamental. Seu foco não é tratar unicamente a Alfabetização Matemática ou a Educação Inclusiva ou a relação entre ambas.

O processo de alfabetização no PNAIC não é entendido de maneira linear, onde primeiro se alfabetiza em língua materna, depois em Matemática e assim por diante. Durante o curso de formação foram abordadas várias temáticas, que podemos considerar essenciais para o trabalho do professor que alfabetiza. Ao procurarmos no material indicações da temática deste trabalho encontramos temas de formação como: Educação especial: a alfabetização de crianças com deficiência: uma proposta inclusiva (BRASIL, 2012a), Currículo inclusivo: o direito de ser alfabetizado (BRASIL, 2012c), Educação Inclusiva (BRASIL , 2014a), Jogos na Alfabetização Matemática (BRASIL, 2014c), Currículo na perspectiva da inclusão e da diversidade: as Diretrizes Curriculares Nacionais da Educação Básica e o ciclo de alfabetização. (BRASIL, 2015a), A criança no ciclo de alfabetização (BRASIL, 2015b), A organização do trabalho escolar e os recursos didáticos na alfabetização (BRASIL, 2015c), Alfabetização matemática na perspectiva do letramento (BRASIL, 2015d), etc. Consideramos que a abordagem que proposta nesse estudo é coerente, pois a perspectiva inclusiva está explicita no programa de formação.

A proposta de currículo inclusivo adotada pelo PNAIC, defende o direito de aprender para "todas" as crianças.

Consequentemente, pelo viés desse currículo, é dever da escola garantir condições favoráveis de aprendizagem, considerando as diferentes trajetórias de vida dos estudantes. Nessa perspectiva, a avaliação é vista como intrinsecamente ligada às ações de ensino, servindo como ponto de partida para o planejamento didático, rompendo com a concepção excludente de avaliação para reprovação. (BRASIL, 2015a, p. 31).

O princípio da inclusão no PNAIC busca o desafio de garantir o direito de alfabetização plena às crianças dentro do Ciclo de Alfabetização. Para isso adota uma perspectiva de avaliação onde os ciclos são um processo inclusivo e fundamental, onde deve haver uma maior flexibilidade com o tempo e mais continuidade do processo de ensino e aprendizagem da Alfabetização. 
Ao adotar a perspectiva inclusiva no currículo, a formação oferecida procura fomentar nos professores a importância de oportunizar o "acesso aos bens científicos e culturais produzidos pela humanidade e inserção nas mais diversificadas práticas sociais, sem discriminação de espécie alguma." (BRASIL, 2015b, p. 59) Garantir um currículo inclusivo é uma forma de integração social de todas as crianças, para isso a compreensão dos conceitos matemáticos é essencial em nossa sociedade, mas não pode estar associado apenas a algumas áreas do currículo escolar, mas deve perpassar todas e de maneira interdisciplinar.

Buscando a efetivação de um currículo inclusivo, o PNAIC destaca a função do planejamento, pois neste momento o professor "reflete sobre as suas ações, sobre as possibilidades e conhecimentos prévios dos alunos, criando oportunidades diferenciadas para a formação de todos, para seguir em frente sem excluir ninguém" (BRASIL, 2015d, p. 53), seja para alunos da Educação Especial, Educação do Campo, Educação Indígena, Quilombola e Educação para as relações Étnico-Raciais. Consideramos ser no momento do planejamento que o professor determina que sua atuação seja em prol da aprendizagem de todos os alunos ou se em função da transmissão de um determinado conteúdo.

Pensar a "organização do trabalho pedagógico para a Alfabetização Matemática envolve as diferentes formas de planejamento, desde a organização da sala até o fechamento da aula, entendidos de forma articulada e que orientam a ação do professor alfabetizador." (BRASIL, 2014d, p. 06) A diversidade precisa ser levada em conta para o desenvolvimento de práticas pedagógicas inclusivas na escola. Por isso para o programa, "um ponto fundamental aqui considerado é o que se postula como Educação Inclusiva" (BRASIL, 2015c, p. 100) Concordamos com a concepção do PNAIC que cabe ao professor refletir sobre o que, por que, para quem ensina e que tempo precisa realizar esse processo, tendo uma ação didática articulada, organizada e, principalmente, inclusiva. Pois é no momento de planejamento que: 
[...] o professor reflete sobre as suas ações, sobre as possibilidades e conhecimentos prévios dos alunos, criando oportunidades diferenciadas para a formação de todos, para seguir em frente sem excluir ninguém, pois as políticas educacionais asseguram a inclusão das crianças da Educação Especial, Educação do Campo, Educação Indígena, Quilombola e Educação para as relações Étnico-Raciais. Portanto, a diversidade deve ser levada em conta para o desenvolvimento de práticas pedagógicas inclusivas na escola. (BRASIL, 2015a, p. 52-53).

Ao focarmos a Alfabetização Matemática, consideramos que esse processo deve voltar-se para a perspectiva do letramento, ou seja, para os usos sociais dos conceitos matemáticos.

Para isso, o trabalho pedagógico deve voltar-se para todos os eixos de conhecimento da área Matemática. Trata-se de uma preocupação voltada para a democratização do saber através da apropriação do conceito de número, da aquisição da representação numérica do sistema decimal, das operações na resolução de problemas, da geometria, das grandezas e medidas, de noções de estatística, dentre outras. (BRASIL, 2015a, p. 28).

Nesse processo é também necessário que todos aprendam os conceitos matemáticos, pois os direitos de aprendizagem são para todos os alunos e por sabermos que "ao contrário do que muitas vezes se pensa, crianças que fazem parte da Educação Especial também gostam e aprendem Matemática”. (BRASIL, 2015a, p. 63)

Dentro da proposta de formação do PNAIC houve uma maior ênfase sobre a Educação Inclusiva durante o ano de 2014, no curso de Matemática, por isso mesmo sendo consciente que essa perspectiva no PNAIC não se vincula somente à Matemática, observamos uma relação mais estreita entre a Educação Inclusiva e a Educação Matemática dentro do programa, algo que incorpora os debates atuais da Educação Matemática Inclusiva.

A Educação Inclusiva foi tema de um dos cadernos do curso de formação matemática, PNAIC Educação Inclusiva (BRASIL, 2014a), e entre os objetivos elencados estão:

[...] ampliar conhecimentos sobre aspectos legais referentes à Educação Especial na perspectiva da Educação Inclusiva; • aprofundar conhecimentos sobre encaminhamentos destinados aos alunos que fazem parte do público alvo da Educação Especial; • ampliar conhecimentos sobre espaços de aprendizagem dos alunos com deficiência, transtornos globais do 
desenvolvimento e altas habilidades/superdotação no contexto da inclusão escolar, ou seja, o trabalho da escola comum articulada com o atendimento educacional especializado - AEE; - compreender a importância de um trabalho considerando as diferenças dos alunos com ações voltadas a promover o acesso, a participação e a aprendizagem dos mesmos; • sugerir práticas pedagógicas de alfabetização matemática para alunos com necessidades específicas. (BRASIL, 2014a, p. 05) (grifo nosso).

Apesar dos objetivos do caderno de formação demonstrarem, certa linearidade no tratamento da temática de Educação Inclusiva, algo comum em outras publicações no MEC; ao colocar como objetivo "sugerir práticas pedagógicas de alfabetização matemática para alunos com necessidades específicas" há congruência com as pesquisas que tratam da Educação Matemática Inclusiva, na propositura de práticas que optamos chamar de "Alfabetização Matemática Inclusiva".

Apesar de destacar que o foco do caderno não ser a Matemática ou a Educação Matemática, ele busca "servir de instrumento para algo", para "mostrar a necessidade e os objetivos de uma Educação Inclusiva e, além disso, fornecer informações aos professores no sentido de prover amparo legal e institucional para suas ações pedagógicas na direção de tornar efetiva a inclusão". (BRASIL, 2014a, p.06). Resumidamente:

[...] o caderno de Educação Inclusiva na coleção de Alfabetização Matemática compila um amplo leque de informações sobre as políticas oficiais presentes no site do MEC em diversas publicações. Além disso, na medida do possível - e sem "forçar" situações descabidas - apresenta alguns encaminhamentos referentes à Alfabetização Matemática. (BRASIL, 2014a, p. 05-06).

De acordo com o discurso institucional do PNAIC, não há sentido realizar uma proposta educativa que garanta os direitos de aprendizagem dos alunos, se não pretendermos que a palavra "alunos" se refira a "todas" as crianças das nossas escolas. Nesse sentido, somente quando conseguirmos agir sem nos preocuparmos com estratégias especiais para a Matemática ou a linguagem ou a geografia... "só então é que estaremos vivenciando, em nós mesmos, a inclusão. Enfim, não fugimos à responsabilidade de sugerir práticas referentes a conteúdos 
matemáticos, mas enfatizamos a precedência do "pensar inclusivamente" ". (BRASIL, 2014a, p. 06).

Ao enfatizar a relação entre o professor de classe e o do $\mathrm{AEE}^{2}$, o PNAIC ressalta que o "professor da sala de aula comum é o responsável pelo ensino da Matemática e ao professor do AEE cabe conhecer o que o aluno sabe em função de suas experiências de vida." (BRASIL, 2014a, p. 30) É de extrema importância a articulação entre o trabalho do professor da sala de aula e o professor do AEE.

No caderno de Educação Inclusiva é realizado o tratamento de cada uma das deficiências, onde os textos estão estruturados da seguinte forma: "para cada uma das formas de deficiência nós explicitaremos as condições de funcionamento do AEE, sempre associadas à sala de aula regular, exemplificando com aspectos da Alfabetização Matemática." (BRASIL, 2014a, p. 21) Para demonstrar, tratamos de algumas indicações feitas no material do PNAIC para o trabalho com alunos com deficiência intelectual. Destacando que para a Alfabetização Matemática, é inadequado o professor propor listas de exercícios mecânicos e repetitivos, pois para esses alunos essas atividades serão completamente "sem sentido".

[...] visto que a repetição de uma atividade não leva à compreensão da outra. Nesse sentido, a ação pedagógica será melhor sucedida caso se proponha atividades de aprendizagem que sejam próximas aos interesses dos alunos, com base em experiências que eles tenham vivenciado. É necessário que os alunos sejam capazes de estabelecer a pertinência da aprendizagem proposta pelo professor em situações reais ou concretas da experiência escolar [...]. (BRASIL, 2014a, p. 28).

Todo sujeito - seja criança, jovem, adulto, deficiente ou não - em processo alfabetização ou não possui a necessidade dos conhecimentos matemáticos para a "leitura" do mundo (FREIRE, 1996). Ao tratar da Alfabetização Matemática há o destaque que para os alunos com deficiência intelectual é importante sugerir situações que se relacionam ao cotidiano e para isso é fundamental conhecer o contexto de vida. Quanto mais comum for a situação de ponto de partida, melhor será a compreensão das situações-problema. "O que deve nos preocupar, na

\footnotetext{
${ }^{2}$ Não tratamos especificamente dessa relação em virtude de termos outro foco no trabalho, mas consideramos como vital para o processo de inclusão e aprendizagem.
} 
condição de educadores, é o quanto o aluno deixará de aprender, não porque ele não tenha condições, mas sim porque the negamos seus direitos de aprendizagem". (BRASIL, 2014a, p. 29).

Outro ponto é o trabalho com situações-problema com alunos surdos, onde as dificuldades são maiores que a forma como o enunciado do problema é escrito e apresentado ao aluno para sua compreensão. Muito mais grave é "a forma como a escola media o conhecimento matemático acrescido da falta de proficiência em Libras do professor que lida com o surdo". (BRASIL, 2014a, p. 33)

Para as crianças cegas, o PNAIC afirma que a falta de acessibilidade física ou de comunicação prejudica de modo decisivo o processo de aprendizagem. "Essas crianças - como qualquer criança - precisam de um ambiente que favoreça o seu processo de alfabetização e letramento, para isso precisam ter as possibilidades de brincar e participar de todas as situações no contexto escolar." (BRASIL, 2014a, p. 39) Destaca o trabalho de Orientação e Mobilidade (OM) para desenvolver autonomia na locomoção tanto no ambiente escolar quanto fora dele. Mover-se de forma orientada, com sentido, direção e utilizando de várias referências são importantes para se chegar ao local desejado e é um trabalho de referência importante no contexto da alfabetização matemática.

Também defende que para o letramento da criança cega, seja em língua materna ou Matemática, é necessário o aprendizado do Sistema Braille, por considerar que ensino e aprendizagem realizados somente através da oralidade e áudio para essa criança, principalmente durante a alfabetização, não é suficiente.

É como se a criança que enxerga fosse para a escola e não aprendesse a ler e escrever, vivenciando somente práticas pedagógicas com uso da oralidade e programas com áudio, sem qualquer forma de registro escrito. Todas as crianças têm o direito, podem e precisam aprender a ler e escrever para obter este tipo de acesso e autonomia em relação ao conhecimento acumulado e organizado. (BRASIL, 2014a, p. 67).

Para trabalhar com alunos que possuem deficiência física destaca recursos que podem ampliar a comunicação, como a prancha de comunicação, pranchas alfabéticas e de palavras, a construção de cartões de comunicação, símbolos de comunicação pictórica, vocalizadores e computadores. Tanto em relação à 
Alfabetização Matemática quanto em relação ao aprendizado de língua materna, há a necessidade de estratégias especiais, focada nas potencialidades do aluno, para assegurar formas de comunicação que incluam os alunos nos processos de ensino. Desde cedo as crianças podem iniciar o uso das tecnologias, familiarizando-se com o teclado, jogos e softwares com leitores de tela e outras possibilidades das Tecnologias da Informação e Comunicação (TIC).

Outro ponto importante apresentado no material de formação é que durante os textos são apresentados exemplos elucidativos de situações que precisam ser melhor compreendidas nas escolas, como por exemplo, a confusão entre a surdez e a capacidade intelectual. Os professores, às vezes, tratam o deficiente auditivo como se também possuísse pouca capacidade intelectual. Deixando claro que em relação ao deficiente auditivo suas limitações são auditivas e não intelectuais ou de outra área. Como exemplo destaca a situação de um professor que não admitia que alunos surdos participassem de um time de futebol nos jogos colegiais; quando indagado sobre a razão da impossibilidade ele respondeu: "É que surdo corre menos". (BRASIL, 2014a, p. 33).

No caderno (BRASIL, 2014a) encontramos atividades onde os professores planejam formas de desenvolver habilidades matemáticas, como por exemplo: "associar a escrita de um número em linguagem corrente à sua escrita em linguagem simbólica e vice-versa", com os alunos com deficiência visual, deficiência motora e surdez.

São propostas questões para reflexões em grupo: você já passou pela experiência de receber um aluno "especial" na sua sala? Já reclamou da sua incapacidade para lidar com ele? Viu algum dos seus colegas na mesma situação e fazendo esse tipo de reclamação? (BRASIL, 2014a, p. 08) Busca-se oportunizar aos professores momentos de reflexão sobre questões e procura encontrar formas, articuladas a sua vivência profissional, para pensar em práticas de Alfabetização Matemática que não sejam excludentes.

Há atividades para realizar em duplas ou grupos que contemplam: a elaboração de um plano de AEE para alunos surdos, cegos, com deficiência física 
ou deficiência intelectual, contemplando a Alfabetização Matemática; adaptação de jogos do caderno Jogos na Alfabetização Matemática (BRASIL, 2014c) para alunos com deficiência; discussão com os colegas para fazer uma lista de modificações que tornariam viáveis alguns jogos conhecidos para o trabalho com alunos surdos, cegos, com deficiência física e deficiência intelectual.

Todo esse processo é extremamente potencializador/fomentador de práticas de Alfabetização Matemática Inclusiva nas classes de $1^{\circ}$, $2^{\circ}$ e $3^{\circ}$ ano do ensino fundamental.

Evidentemente, essa perspectiva inclusiva não se deu apenas em 2014, no primeiro ano de formação foram discutidos no Caderno de Educação especial: a alfabetização de crianças com deficiência: uma proposta inclusiva (BRASIL, 2012a) relatos de experiências com a inclusão, o uso de jogos voltados para a alfabetização inclusiva e sugestões de leitura de textos de temática inclusiva. "Embora nem todos os cadernos façam menção explícita à Educação Inclusiva ou à Educação do Campo, eles foram concebidos de modo articulado com o conteúdo dos cadernos de referência, podendo ser utilizados de modo complementar." (BRASIL, 2014b, p. 17).

No programa também há o destaque para que as atividades do Caderno de Jogos na Alfabetização Matemática (BRASIL, 2014c) possam ser utilizadas por "todos" os alunos, necessitando apenas que suas especificidades sejam consideradas. Aborda que as intervenções indicadas não são as únicas possíveis, mas são fundamentais para se pensar no processo educacional dos alunos.

Consideramos que a formação oferecida no curso do PNAIC está de acordo com as considerações de Kranz (2011).

A princípio, seria uma formação na perspectiva de fazer com os professores, e não para eles, entendendo-os como sujeitos aprendentes, com saberes e não saberes. Também uma formação que possa (re)pensar as concepções que norteiam a aprendizagem matemática dos alunos com deficiência, no que diz respeito à deficiência, à Matemática, à aprendizagem e ao desenvolvimento infantil. (KRANZ, 2011, p. 133).

Para Manrique e Moreira (2014) a formação contínua é uma forma de minimizar atitudes negativas em relação aos alunos com NEE. Para os autores, 
se os cursos acontecessem com maior frequência, intensidade e fossem gratuitos, teríamos resultados mais significativos. Esta afirmação vai ao encontro com o curso ofertado no PNAIC, uma formação continuada para professores em atuação, com bolsa de estudos para todos os cursistas.

Pela nossa análise o curso de formação do PNAIC, mesmo não sendo voltado exclusivamente para a Educação Matemática Inclusiva, ou melhor, Alfabetização Matemática Inclusiva, possui estreita relação com a inclusão de "todos" os alunos, ressignificando materiais e a mediação pedagógica no contexto do ensino dessa área do currículo escolar. O programa oportuniza encaminhar ideias que possibilitam aos professores desenvolver um trabalho pedagógico com os alunos; de modo que as pessoas são e aprendem de modo diferente e só aprenderão se tiverem as condições necessárias para participar do processo de aprendizagem.

Ao analisar o material de formação do programa refletimos que ele pode tanto proporcionar elementos para a reflexão pedagógica dos professores, como subsidiar nas suas práticas ações efetivas de inclusão.

\section{Considerações Finais}

Julgamos a formação continuada de docentes dentro do PNAIC como potencialmente significativa para fomentar uma prática educativa voltada para a Educação Inclusiva nos primeiros anos de escolarização e, mais especificamente, para uma Alfabetização Matemática Inclusiva.

Com este trabalho percebemos fortes indicativos da Educação Matemática Inclusiva no curso de formação do PNAIC, onde são propostas novas interpretações e alternativas de ação pedagógica com vistas à inclusão de todos alunos nos processos de ensino e aprendizagem.

Observamos possibilidades de Alfabetização numa perspectiva de Educação Matemática Inclusiva, onde as diferenças entre os alunos podem enriquecer o processo de ensino. A busca por um processo de ensino inclusivo, 
principalmente, sobre como buscar novas configurações para os processos de aprendizagem para crianças com deficiência nas classes regulares, beneficia todos os alunos que precisam usufruir da rotina escolar, acessar o currículo e o conteúdo pedagógico proposto de diferentes formas.

A Alfabetização Matemática é um instrumento para a leitura do mundo e supera a simples decodificação e a resolução das quatro operações básicas. Para auxiliar esse processo, a perspectiva inclusiva busca estratégias pedagógicas, que construam oportunidades reais de aprendizagem para todos os alunos. Permite a interação de todas as crianças, leva em consideração as peculiaridades $\mathrm{e}$ as diversas maneiras de aprender. Evidentemente que as dificuldades enfrentadas no processo de ensino pelos professores não se restringem aos alunos NEE; por isso é fundamental que os professores sejam capacitados para ajustar o seu fazer pedagógico às necessidades dos educandos, sejam com NEE ou não. (FERNANDES; HEALY, 2007).

Ao oportunizar um curso de formação onde se trata de uma Alfabetização Matemática numa perspectiva inclusiva há a oportunidade de se mudar a compreensão do professor acerca do que seja Matemática, pois sabemos que toda prática ou teoria pedagógica, de modo consciente ou não, é influenciada pela concepção filosófico-pedagogica do educador.

O PNAIC, como um instrumento para algo, oportuniza que os professores pensem sobre o que fazer; como ensinar, quais recursos utilizar, etc. questões que intrigam os docentes ao receber alunos com NEE, pois não se sentem seguros para conduzir a aprendizagem dessas crianças. Mesmo os professores alfabetizadores mais experientes possuem questões que os afligem, a falta de material de apoio pedagógico adequado para o trabalho com alunos NEE é uma delas e o PNAIC oportuniza formas de criar/adaptar estratégias e fornecer subsídios teóricos e práticos para a educação destes alunos.

Autores como Moreira (2015) têm demonstrado a necessidade de ofertar cursos para sanar algumas defasagens da formação inicial dos docentes, munindo-os de informações acerca dos processos de inclusão do aluno NEE. 
Asseveramos que esse curso de formação tem potencial, principalmente, para fomentar práticas de Alfabetização Matemática Inclusiva. Entretanto, os cursos precisam ir além de tratar a legislação em que se assenta a Educação Especial e os direitos dos alunos NEE; devem fornecer meios para que as aulas se tornem mais inclusivas, que os processos de ensino possam ser reinventados para a aprendizagem de todos. Nesse caminho a Educação Matemática vem buscando uma linha efetivamente inclusiva. Algo que é perceptível no programa de formação do PNAIC.

\section{Referências}

BRASIL. Política Nacional de Educação Especial na perspectiva da Educação Inclusiva. Brasília: MEC, 2008.

Caderno de educação especial: a alfabetização de crianças com deficiência: uma proposta inclusiva. Brasília: MEC, SEB, 2012a. 48 p.

Portaria № 867, de 4 de julho de 2012b. Institui o Pacto Nacional pela Alfabetização na Idade Certa e as ações do Pacto e define suas diretrizes gerais. Disponível em: http://pacto.mec.gov.br/images/pdf/port 867 040712.pdf . Acesso em: 20 jun 2016.

Pacto nacional pela alfabetização na idade certa: currículo inclusivo: o direito de ser alfabetizado: ano 3: unidade 1. Brasília: MEC, SEB, 2012c. 48 p.

Pacto Nacional pela Alfabetização na Idade Certa: Educação Inclusiva. Brasília: MEC, SEB, 2014a. 96 p.

Pacto Nacional pela Alfabetização na Idade Certa: Apresentação. Brasília: MEC, SEB, 2014b. 72 p.

Pacto Nacional pela Alfabetização na Idade Certa: Jogos na Alfabetização Matemática. Brasília: MEC, SEB, 2014c. 72 p.

Pacto Nacional pela Alfabetização na Idade Certa: Organização do Trabalho Pedagógico. Brasília: MEC, SEB, 2014d. 72 p.

Pacto Nacional pela Alfabetização na Idade Certa. Currículo na perspectiva da inclusão e da diversidade: as Diretrizes Curriculares Nacionais da Educação Básica e o ciclo de alfabetização. Caderno 01. Brasília: MEC, SEB, 2015a. 104 p.

Pacto Nacional pela Alfabetização na Idade Certa. A criança no ciclo de alfabetização. Caderno 02. Brasília: MEC, SEB, 2015b. 112 p. 
Pacto Nacional pela Alfabetização na Idade Certa. A organização do trabalho escolar e os recursos didáticos na alfabetização. Caderno 04. Brasília: MEC, SEB, 2015c. $116 \mathrm{p}$.

- Pacto Nacional pela Alfabetização na Idade Certa. Alfabetização matemática na perspectiva do letramento. Caderno 07. Brasília: MEC, SEB, 2015d. 98 p.

FERNANDES; Solange Hassan Ahmad Ali. HEALY; Lulu. Ensaio sobre a inclusão na Educação Matemática. UNION - Revista Iberoamericana de Educación Matemática. № 10, Junio de 2007. p. 59-76.

A inclusão de alunos cegos nas aulas de matemática: explorando área, perímetro e volume através do tato. Bolema, Rio Claro (SP), v. 23, № 37, p. 1111 a 1135, dezembro 2010.

FREIRE, Paulo. Pedagogia da Autonomia: saberes necessários à prática educativa. São Paulo: Paz e Terra, 1996.

KRANZ; Cláudia Rosana. Os jogos com regras na educação matemática inclusiva. (Dissertação). Programa de Pós-Graduação em Educação da Universidade Federal do Rio Grande do Norte. Orientador: Prof. Dr. Iran Abreu Mendes. 2011.

\section{Os jogos com regras na perspectiva do desenho universal:}

contribuições à educação matemática inclusiva. (Tese) Programa de Pós-Graduação em Educação da Universidade Federal do Rio Grande do Norte. Orientação do Prof. Dr. Iran Abreu Mendes. 2014.

O Desenho Universal na Educação Matemática Inclusiva. XIV CIAEMIACME, Chiapas, México, 2015. p. 01-13.

MOREIRA; Geraldo Eustáquio. A Educação Matemática Inclusiva no contexto da pátria educadora e do novo PNE: reflexões no âmbito do GD7. Educ. Matem. Pesq., São Paulo, v.17, n.3, pp.508-519, 2015.

MOREIRA, Geraldo Eustáquio. MANRIQUE, Ana Lúcia. Percepções de Professores Acerca da Inclusão de Alunos com NEE em Aulas de Matemática em Braga (Portugal) e no Distrito Federal (Brasil). Perspectivas da Educação Matemática - UFMS - v. 7, n. 14 - 2014. P.186-201. Disponível em: http://www.edumat.ufms.br/. Acesso em 15 jun 2016.

STAINBACK, Susan. STAINBACK, Willian. Inclusão - Um Guia para Educadores. Artmed Editora. Porto Alegre. 1996.

VYGOTSKI, Lev Semionovitch. Obras Escogidas V. Fundamentos de defectologia. Madrid: Visor, 1997. 